\title{
The influence of local meteorological conditions on the circadian rhythm of corn (Zea mays L.) pollen emission
}

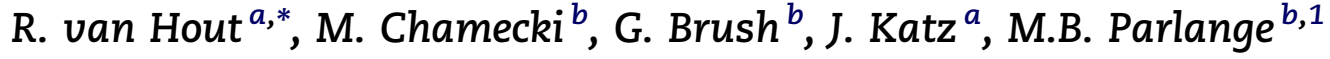 \\ ${ }^{a}$ The Johns Hopkins University, Department of Mechanical Engineering and Center for Environmental and \\ Applied Fluid Mechanics, 3400 N. Charles Street, Baltimore, MD 21218, USA \\ ${ }^{\mathrm{b}}$ The Johns Hopkins University, Department of Geography and Environmental Engineering and \\ Center for Environmental and Applied Fluid Mechanics, 3400 N. Charles Street, Baltimore, MD 21218, USA
}

\section{A R T I C L E I N F O}

Article history:

Received 15 March 2007

Received in revised form

17 February 2008

Accepted 22 February 2008

Keywords:

Canopy flows

Corn (Zea mays L.)

Diurnal cycles

Ejections

Irradiance

Pollen emission

Pollen concentration

Turbulence

\begin{abstract}
A B S T R A C T
Field experiments were performed to study the diurnal cycle of corn pollen emission and its relation to local meteorological conditions, including temperature, relative humidity, solar radiation, mean wind speed, and turbulence quantities. Pollen concentrations were measured from canopy height to twice this level using four Rotorod samplers located on a pole in the middle of the corn field. The measured pollen concentration at canopy height was used as a surrogate for the pollen source strength while the concentrations above canopy represented the pollen transported upwards from canopy height. At twice the canopy height, the pollen concentration decreased considerably to about $30 \%$ of the canopy height values. During the mornings, pollen was emitted in large quantities while during the afternoons, airborne pollen concentrations decreased and no significant atmospheric pollen was measured from about $2 \mathrm{~h}$ prior to sunset until sunrise the next morning. The actual time that airborne pollen was first recorded differed from day-to-day and depended on the time required for the anthers to dry and open, as well as there being sufficiently strong winds to entrain the pollen away from the plants. On four consecutive mornings diurnal atmospheric pollen concentration distributions were bi-modal in time. The first pollen concentration peak happened shortly before the direct irradiance peak on the anthers suggesting that direct solar irradiation might be important for drying the anthers. The subsequent dip in pollen concentration seemed to be linked to a lull in mean and turbulent wind conditions. Analysis of the vertical velocity fluctuations, $\sigma_{\mathrm{w}}$, showed that the fraction of pollen transported upwards from canopy height increased with increasing $\sigma_{\mathrm{w}}$. In addition, QuadrantHole analysis applied to the turbulence data sets of 2 days suggested that low values of ejection duration fractions were associated with low values of pollen concentration, while high values were associated with high concentration values. The diurnal pattern of ejection duration fractions was similar to the pattern of the fraction of pollen that reached twice the canopy height, indicating the important effect of large-scale coherent ejections on pollen transport.
\end{abstract}

(C) 2008 Elsevier B.V. All rights reserved.

\footnotetext{
* Corresponding author. Current address: Technion - IIT, Faculty of Mechanical Engineering, Technion City, Haifa 32000, Israel.

Tel.: +972 4 8293866; fax: +972 48295711 .

E-mail address: rene@technion.ac.il (R. van Hout).

${ }^{1}$ Also at: School of Architecture, Civil and Environmental Engineering, École Polytechnique Fédérale de Lausanne 1015, Switzerland. 0168-1923/\$ - see front matter (C) 2008 Elsevier B.V. All rights reserved.

doi:10.1016/j.agrformet.2008.02.009
} 
1.

Introduction

Community interest in wind dispersal (anemophely) of pollen grains has increased due to potential impacts on biologic diversity associated with the benefits and dangers of genetically modified food crops (Wolfenbarger and Phifer, 2000; Aylor et al., 2003), as well as the maintenance of genetic diversity in a landscape of increasingly small isolated patches of vegetation (Honnay et al., 2005). Of major importance in these discussions is the distance that pollen grains can be dispersed from their source. This subject has been studied using genetic markers (e.g. Messeguer et al., 2001; Klein et al., 2003; Loos et al., 2003; Watrud et al., 2004), and by measuring pollen concentrations in the air at different distances from the emitter field (e.g. Raynor et al., 1972; Jarosz et al., 2003, 2005). In addition, different models have been developed to predict pollen dispersal patterns (e.g. Wilson, 2000; Klein et al., 2003; Loos et al., 2003; Jarosz et al., 2004; Aylor, 2005).

Several studies have focused on corn pollen dispersal. Raynor et al. (1972) measured the downwind dispersal and concentration profiles of corn pollen emitted from an $18.3 \mathrm{~m}$ diameter plot during constant weather conditions. They reported that at $60 \mathrm{~m}$ from the source plot, only $1 \%$ of the corn pollen remained aloft while this percentage increased with increasing wind speed and source plot size. More recently, Jarosz et al. (2003) performed similar measurements on a $20 \mathrm{~m} \times 20 \mathrm{~m}$ corn field surrounded by $120 \mathrm{~m} \times 122 \mathrm{~m}$ of barren land beyond which more corn was planted. Their experiments were limited to mean velocities lower than $1 \mathrm{~m} \mathrm{~s}^{-1}$ to avoid contamination of the measurements by the surrounding corn. Vertical profiles of downwind pollen concentrations and fluxes were obtained at 3 and $10 \mathrm{~m}$ from the source, using rotating-arm spore traps mounted on poles, $4 \mathrm{~m}$ high. Pollen concentrations decreased by about a factor of 3 , between 3 and $10 \mathrm{~m}$ downwind of the source with a peak concentration located below $2 \mathrm{~m}$.

In the present paper, the measured pollen concentration at canopy height is used as a surrogate for the pollen source strength ("pollen production") while the concentrations above canopy represent the pollen transported upwards from the pollen source (i.e. the tassels) located at canopy height.

At the source, pollen emission depends on biological processes that must occur within the plant before pollen is emitted. Corn plants are monoecious, i.e. they have male and female flowers on the same plant. The male floral structure called the tassel is partly shown in Fig. 1. It is located at the top of the plant and contains a few hundred to a thousand spikelets; each spikelet supports two male flowers that contain three anthers each. Once anthers are extended, pollen emission is initiated by desiccation of the anther tip (Aylor et al., 2003). When corn pollen grains are almost mature, the anther consists of four locules and the tissue between each two bordering locules is referred to as the septum. Keijzer et al. (1996), in their study on corn anther maturation, described anatomical and morphological changes prior to flowering (anthesis). The septum was completely closed 4 days prior to anthesis while 1 day prior to anthesis, the four locules were converted into two by the disintegration of the septum between two adjacent locules. During anthesis, desiccation caused the locule walls at the tip of the anther to bend

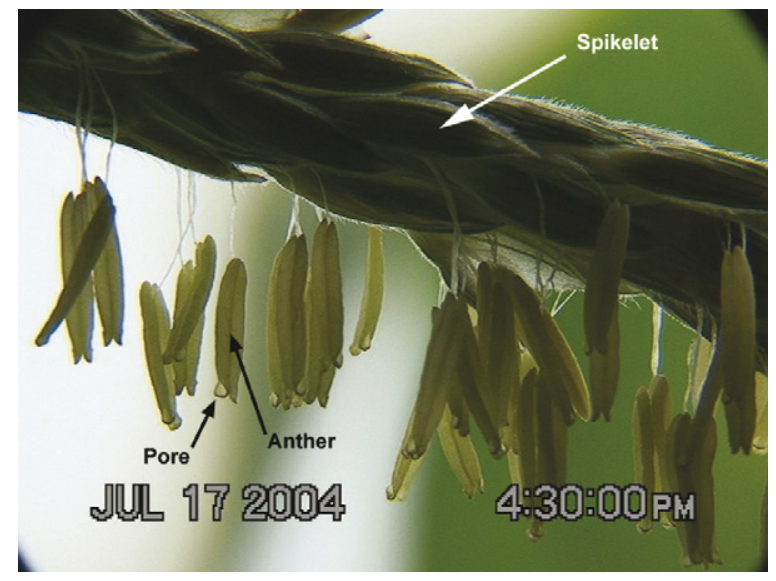

Fig. 1 - Example of a part of a tassel with the anthers extended from the spikelets (not to scale).

outward, ultimately forming a pore (Fig. 1) through which pollen was emitted by any slight movement of the anther, e.g. caused by wind. Evaporation as well as active retraction of water from the anther by the plant have been proposed as possible mechanisms for desiccation of the anther (Bonner and Dickinson, 1990; Heslop-Harrison et al., 1987). Anther opening (dehiscence) was observed to be reversible and rehydration of the anthers closed the pore within seconds.

Some attention has been directed towards the influence of local meteorological conditions on pollen emission. It has, however, been difficult to conclusively relate the multiple meteorological parameters such as temperature, relative humidity and wind conditions to the measured pollen concentration patterns (e.g. McDonald, 1980; Jackson and Lyford, 1999; Galán et al., 2000). Jackson and Lyford (1999) stated that cool, cloudy and especially humid conditions led to temporary suppression of pollen emission while Jarosz et al. (2003) commented that pollen emission in the morning appeared to coincide with the drying of the crop. Recently, Jarosz et al. (2005) related the initial morning emission of corn pollen to a decrease in relative humidity characterized by vapor pressure deficit (VPD) values of $0.2-0.5 \mathrm{kPa}$ around the anthers. As soon as the anthers are open and pollen is emitted, transport of pollen into the atmosphere is governed by the grain's size, shape and mass as well as the aerodynamic forces generated by the airflow over and within the crop canopy. Competing processes of mean advection, turbulence and gravitational settling as well as interception by, deposition on and rebound from leaves and other plant parts (Aylor et al., 2003), ultimately determine the shape of the pollen dispersal "plume".

Past field measurements of the circadian rhythm of corn pollen emission displayed high emission rates during morning hours (Ogden et al., 1969; Flottum et al., 1984; Jarosz et al., 2003). The pollen emission cycles that Flottum et al. (1984) measured, were bi-modal showing an initial morning peak, a subsequent decrease and a second smaller peak in pollen concentration occurring within $4 \mathrm{~h}$. They did not link the bimodal distributions to local meteorological conditions. Corn pollen emission was not observed before sunrise or after 
sunset. In all these studies, any relationship between the diurnal cycle of corn pollen emission and local meteorological conditions was not studied in detail.

The aim of the present paper is to present detailed simultaneous measurements of the corn pollen emission rate and local meteorological conditions, i.e. temperature, humidity, radiation, mean wind speed and turbulence quantities that may influence the circadian rhythm of corn pollen emission into the atmosphere. Subsequently, these data are used to suggest possible explanations for the observed diurnal, pollen emission patterns.

\section{Experimental setup and conditions}

Field measurements were carried out from 12 July until 21 July 2004 , on the eastern shore of the Chesapeake Bay, in Maryland, USA (latitude $38^{\circ} 54^{\prime} 45^{\prime \prime} \mathrm{N}$; longitude $76^{\circ} 9^{\prime} 4^{\prime \prime} \mathrm{W}$ ). The field site was a flat, $\sim 0.2 \mathrm{~km}^{2}$ corn field. During the course of the experiments the corn plants were fully matured and pollinating. Within the measurement site, the average corn height $(h)$ was $3 \mathrm{~m}$, measured from the ground to the top of the tassels.

Three different towers, two measuring local meteorological conditions and the third measuring vertical profiles of pollen concentration, were positioned near the center of the field as shown schematically in Fig. 2. Local meteorological conditions, averaged over 15 min intervals, were monitored con- tinuously by a National Oceanic and Atmospheric Administration (NOAA) weather station, positioned in the center of the field, approximately $30 \mathrm{~m}$ from our experimental setup. The NOAA weather station consisted of a propeller wind vane and a pyranometer located at $z / h=3$, where $z$ is the vertical distance measured from the ground. A temperaturehumidity sensor and a rain gauge were located at $z / h=2$. A second meteorological station, measuring both the mean and the turbulence parameters for the duration of the experiments, consisted of two 3D Campbell Scientific sonic anemometers/thermometers with sampling lengths of $\sim 10 \mathrm{~cm}$, mounted at $z / h=1$ and $z / h=1.5$, an $R M$ Young propeller wind vane at $\mathrm{z} / \mathrm{h}=2$, two Vaisala Hygrometers/ Thermometers at $z / h=1.2$ and $z / h=1.7$, and a Texas Electronics Rain Gauge placed above the canopy. Data were collected continuously at $10 \mathrm{~Hz}$ and mean and turbulence quantities were calculated for 15 min intervals. For each interval, the data set of the sonic anemometers was virtually rotated, thus aligning the sonic anemometers with the mean streamwise wind direction. In the following, mean velocities are indicated by upper case and fluctuating velocities by lower case, i.e. $U, V$, $\mathrm{W}$ and $u, v, w$ are the mean and fluctuating velocities in the streamwise, spanwise and vertical ( $x, y, z)$ directions, respectively.

Vertical profiles of corn pollen concentrations were sampled using four Rotorod (Multidata LLC) rotating impact samplers (May et al., 1976; Mullins and Emberlin, 1997; Frenz,

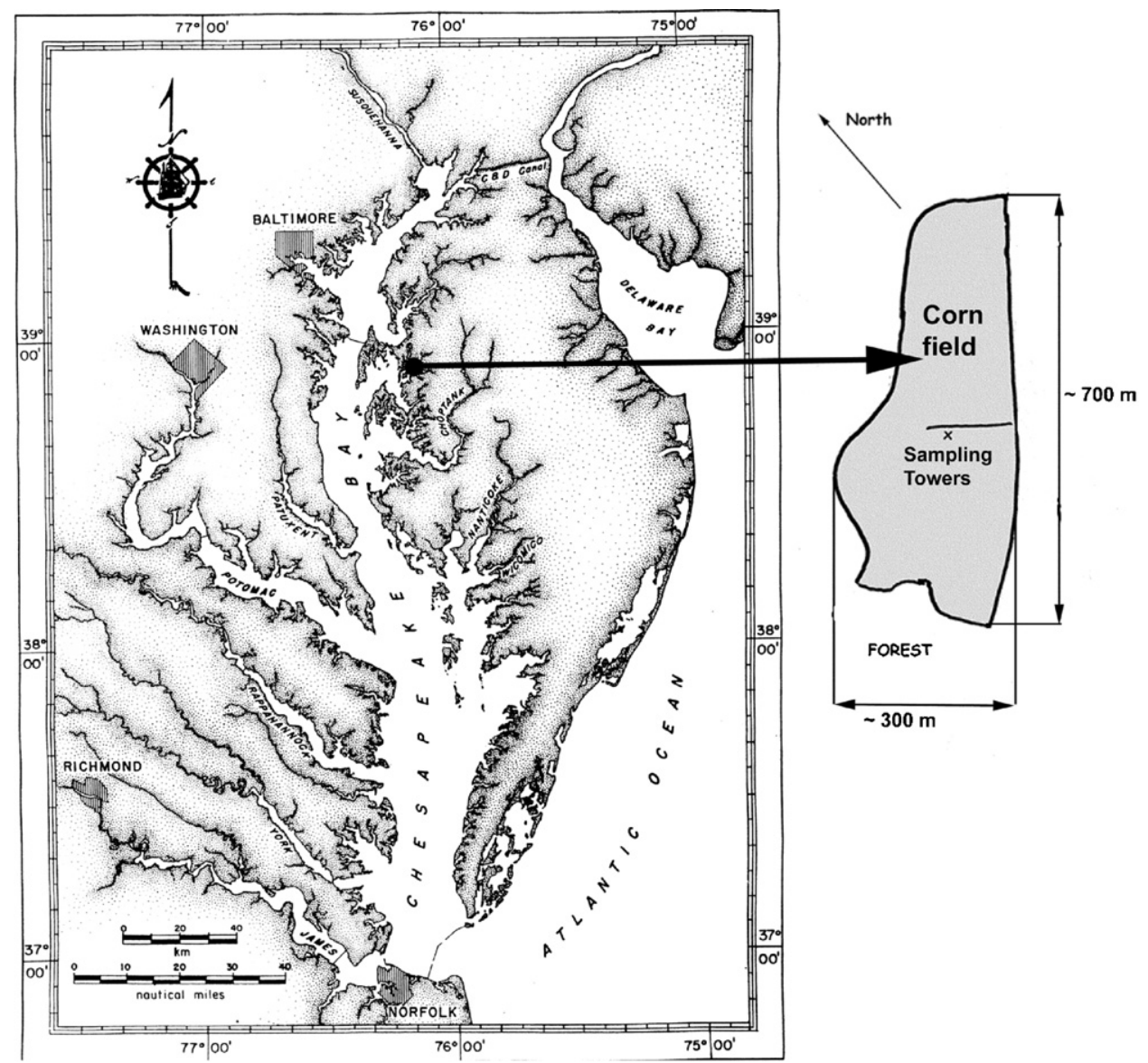

Fig. 2 - Chesapeake Bay (Maryland, USA) and the location of the corn field and sampling towers (not to scale). 


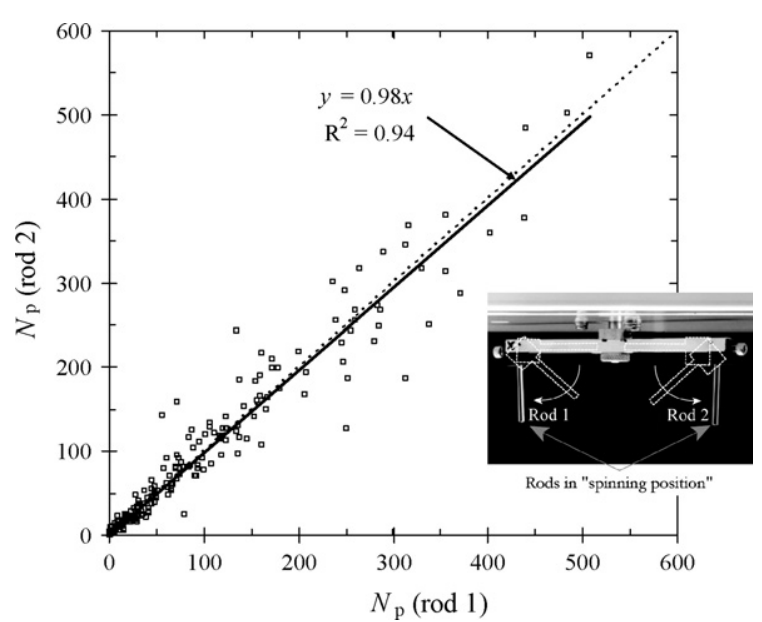

Fig. 3 - Comparison between the pollen counts of the two simultaneously sampled pollen collector rods. Insert: two collector rods located on the spinning bar of the Rotorod pollen sampler.

2000) mounted on a $6 \mathrm{~m}$ high aluminum pole. The four samplers were mounted at $\mathrm{z} / \mathrm{h}=1,1.25,1.5$ and 2 , with a cup anemometer used for measuring mean velocities, mounted at $\mathrm{z} / \mathrm{h}=2$ on the same pole. Each sampler consisted of two spring loaded, transparent plastic square collector rods $(1.52 \mathrm{~mm} \times 1.52 \mathrm{~mm} \times 32 \mathrm{~mm})$ located at the same height and connected to a bar such that upon rotating the bar, the rods were pushed outwards by centrifugal force and became exposed (Fig. 3). During the experiments, the samplers were running at a $100 \%$ duty cycle, i.e. the collector rods were always out in the open. Silicone grease was applied to the side of the rods facing the rotation direction, in order to retain the pollen grains and any other aerosols in the air. The collection efficiency was assumed to be $100 \%$ and independent of the present range of wind speeds. Each day, the collector rods were exchanged on an hourly basis between 0600 EDT (Eastern Daylight Time) and 1200 EDT, and subsequently at two-hourly sampling periods from 1200 EDT to 1800 EDT. Rods were replaced at 1800 EDT and left in the samplers until 0600 EDT the next morning. Exchanging the rods took on average $5 \mathrm{~min}$, during which time they were transferred from the bar to a sterile container.

Upon completing the experiments, the collected pollen grains on each rod were counted manually using an optical microscope (Leica, model DML B) in the laboratory, in order to avoid contamination. A comparison between the pollen counts, $N_{p}$, of the two simultaneously sampled collector rods 1 and 2 is shown in Fig. 3 for all sampling periods. A least square linear fit is displayed with a slope of 0.98 and $R^{2}=0.94$. Differences in pollen counts between the two rods in terms of the maximum daily pollen count for each day ranged from $10 \%$ to $30 \%$. In the following discussion, the average count of the two collector rods for each sampling period is used in the data analysis. Pollen concentration is defined as the number of collected pollen grains divided by the corresponding air volume sampled by the rotating collector rod, $c=N_{p} / V_{r}$. The sampled air volume of one rod is given by $V_{r}=2 \pi r A f t_{s}$ where $r=4.3 \mathrm{~cm}$, is the radius about which the collector rod rotates, $\mathrm{A}$

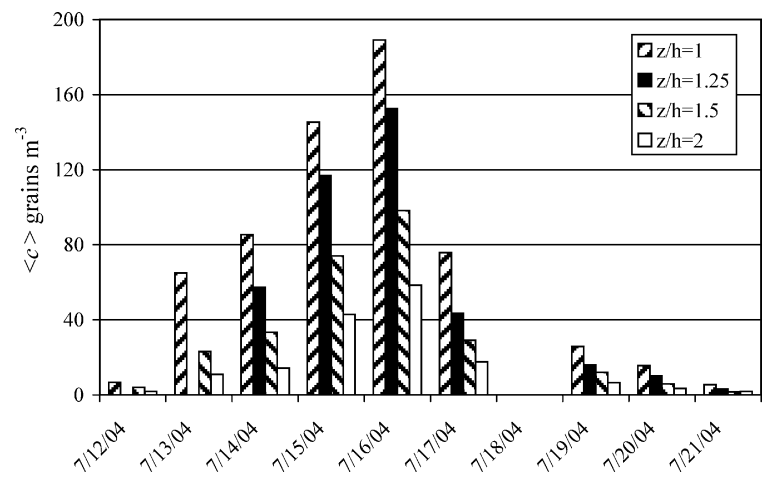

Fig. 4 - Daily pollen concentrations averaged between 0600 EDT and 1800 EDT.

is the rod's effective area $(1.52 \mathrm{~mm} \times 22 \mathrm{~mm}), f$ is the rotation rate of the Rotorod sampler and $t_{\mathrm{s}}$ is the sampling time. Each sampler's rotation rate was carefully calibrated using a digital strobe light. The sampled air volume was about $1 \mathrm{~m}^{3} / \mathrm{h}$. The measured pollen concentrations are normalized by the pollen concentration measured at canopy height, $c(z / h=1) \equiv c_{h}$, used as a surrogate for the pollen production (the source strength) which was not measured directly.

\section{Characteristics of airborne pollen concentration}

Pollen was emitted from 12 July until 21 July 2004. Daily mean pollen concentrations, $\langle c\rangle$, averaged between 0600 EDT and 1800 EDT are shown in Fig. 4 at all measured heights. During most nighttime periods no significant amounts of pollen were sampled. Pollen concentrations increased steadily from 12 July, peaking on 16 July and decreasing afterwards. No pollen was collected on the rods on 18 July, a rainy and cloudy day. Mean pollen concentrations decreased with increasing height; e.g. on 16 July, the pollen concentration at $z / h=1$ equaled 189 grains $\mathrm{m}^{-3}$, and at $\mathrm{z} / \mathrm{h}=2$ reduced to 58 grains $\mathrm{m}^{-3}$.

The diurnal cycle of pollen emission into the atmosphere was measured for 10 consecutive days as described in Section 2. Fig. 5 presents the diurnal variation of pollen concentration, c, at all four measurement heights. We show results only for days with significant pollen concentrations, i.e. from 13 to 17 July and 19 July (Fig. 4). Note that sunrise occurred around 0555 EDT and sunset around 2030 EDT resulting in a difference of about 75 min between solar time and EDT. On all of these days, pollen was emitted after sunrise and peak values of airborne pollen concentration occurred during the morning hours. During afternoons, pollen concentrations decreased except for 14 July between 1400 EDT and 1600 EDT, just prior to a thunderstorm. On 2 days ( 15 and 16 July, Fig. $5 \mathrm{c}$ and d) the start of pollen emission coincided with sunrise while on the other days pollen emission only started between 0900 and 1000 EDT. In all cases, pollen concentrations became negligible $2 \mathrm{~h}$ before sunset. Pollen concentrations decreased with increasing measurement height. Concentrations were highest at canopy height where the tassels were located and pollen was emitted, and decreased at higher elevations. Peak pollen 

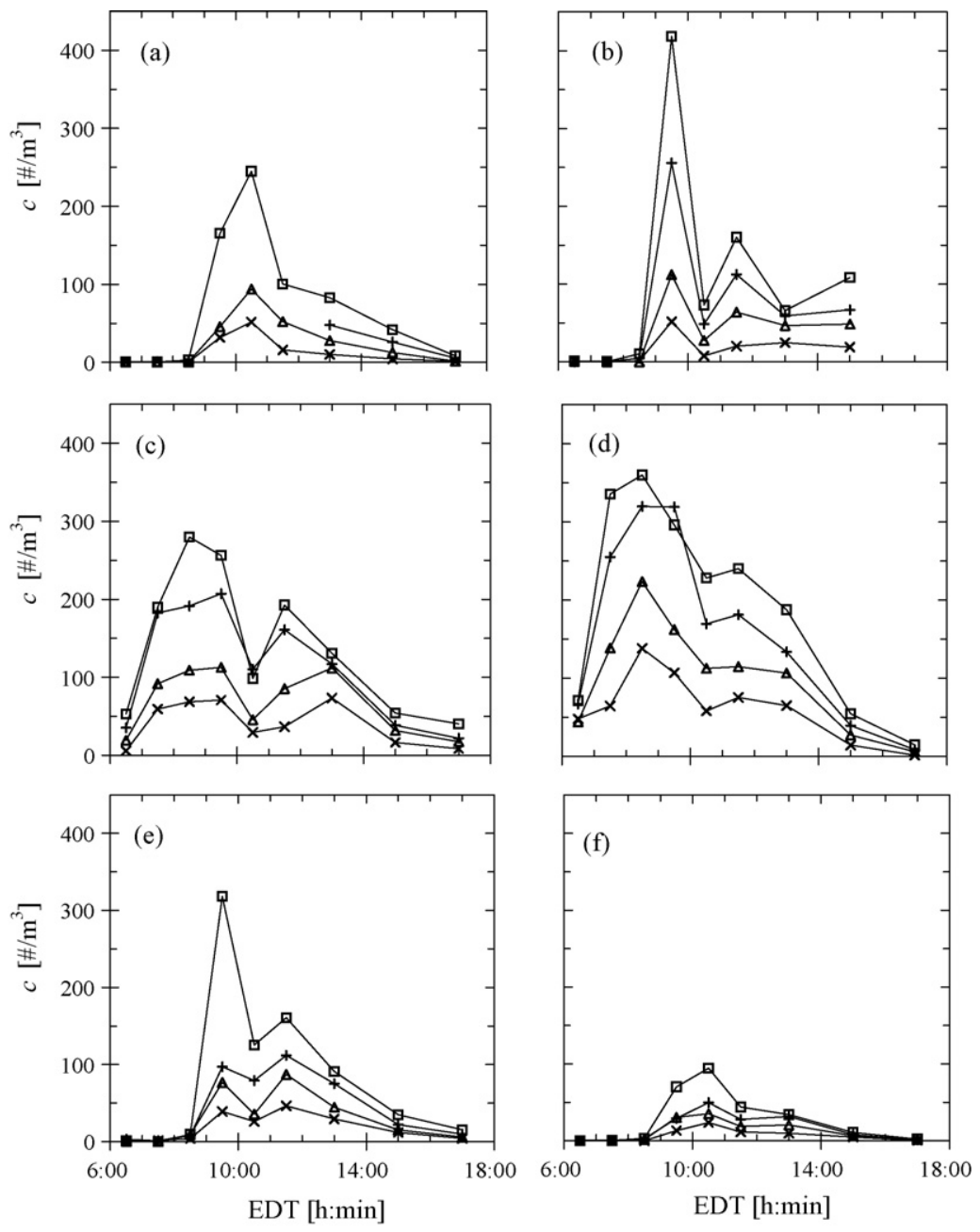

$\rightarrow-\mathrm{z} / \mathrm{h}=1 \rightarrow \mathrm{z} / \mathrm{h}=1.25 \rightarrow \mathrm{z} / \mathrm{h}=1.5 \rightarrow \mathrm{z} / \mathrm{h}=2$

Fig. 5 - Diurnal cycle of corn pollen concentration: (a) 13 July; (b) 14 July; (c) 15 July; (d) 16 July; (e) 17 July; (f) 19 July.

concentrations at canopy height ranged between 250 and 420 grains $\mathrm{m}^{-3}$ from 13 to 17 July and reduced to 95 grains $\mathrm{m}^{-3}$ on 19 July. Also, on four consecutive days (14-17 July, Fig. 5b-e) diurnal distributions of pollen concentration were bi-modal, similar to those measured by Flottum et al. (1984), with a second lesser peak occurring for most elevations between 1100 and 1200 EDT.

The data presented in Fig. 5 show a large variation in the diurnal cycles of pollen emission for different days, so that averaging the data sets would be meaningless. In order to compare the different days, pollen concentrations were normalized by the maximum concentration at canopy height for the same day, $c_{\max }$. A subsequent comparison between diurnal pollen concentration distributions at $z / h=1$ and 2 is presented in Fig. 6 where days exhibiting similar diurnal pollen concentrations are grouped. To emphasize trends, average values are depicted as black squares connected by a thin line. It can be seen clearly that in each group variations of $c\left(t_{s}\right) / c_{\text {max }}$ are small compared to inter-group variations, especially during the mornings. The large inter-group variation is mainly due to the fact that initial morning pollen emission starts at different times for different days. A detailed analysis of the effect of meteorological conditions on the diurnal cycle of pollen emission is presented in Sections 4 and 5 .

Corn pollen size distributions at the lowest and highest measurement height were determined from images of about 200 pollen grains, captured on 16 July between 1100 and 1200 EDT on the Rotorod samplers. The images were taken using a CCD camera (Imaging Micropublisher, $2080 \times 1542$ pixels with pixel size of $3.45 \mu \mathrm{m} \times 3.45 \mu \mathrm{m}$ ) attached to a Leica optical microscope at a magnification of $10 \times$, corresponding to a resolution of $0.345 \mu \mathrm{m} /$ pixel. The images were analyzed using Matlab's image processing toolbox and the projected area diameter was calculated from binary images, $d_{A}=\sqrt{4 A_{p} / \pi}$, where $A_{p}$ is the projected area of the pollen grain. The resulting pollen size distributions are shown in Fig. 7 . The mean pollen diameter at $\mathrm{z} / \mathrm{h}=1$ is $\left\langle d_{\mathrm{A}}\right\rangle=89.4 \mu \mathrm{m}$ with a standard deviation $\sigma=6.9 \mu \mathrm{m}$ while at $\mathrm{z} / \mathrm{h}=2$, the mean value is slightly lower, $\left\langle\mathrm{d}_{\mathrm{A}}\right\rangle=86.0 \mu \mathrm{m}$ and $\sigma=5.7 \mu \mathrm{m}$; the difference in mean values was found to be significant at the $2.5 \%$ level (one-tailed t-test). These values correspond well to those 

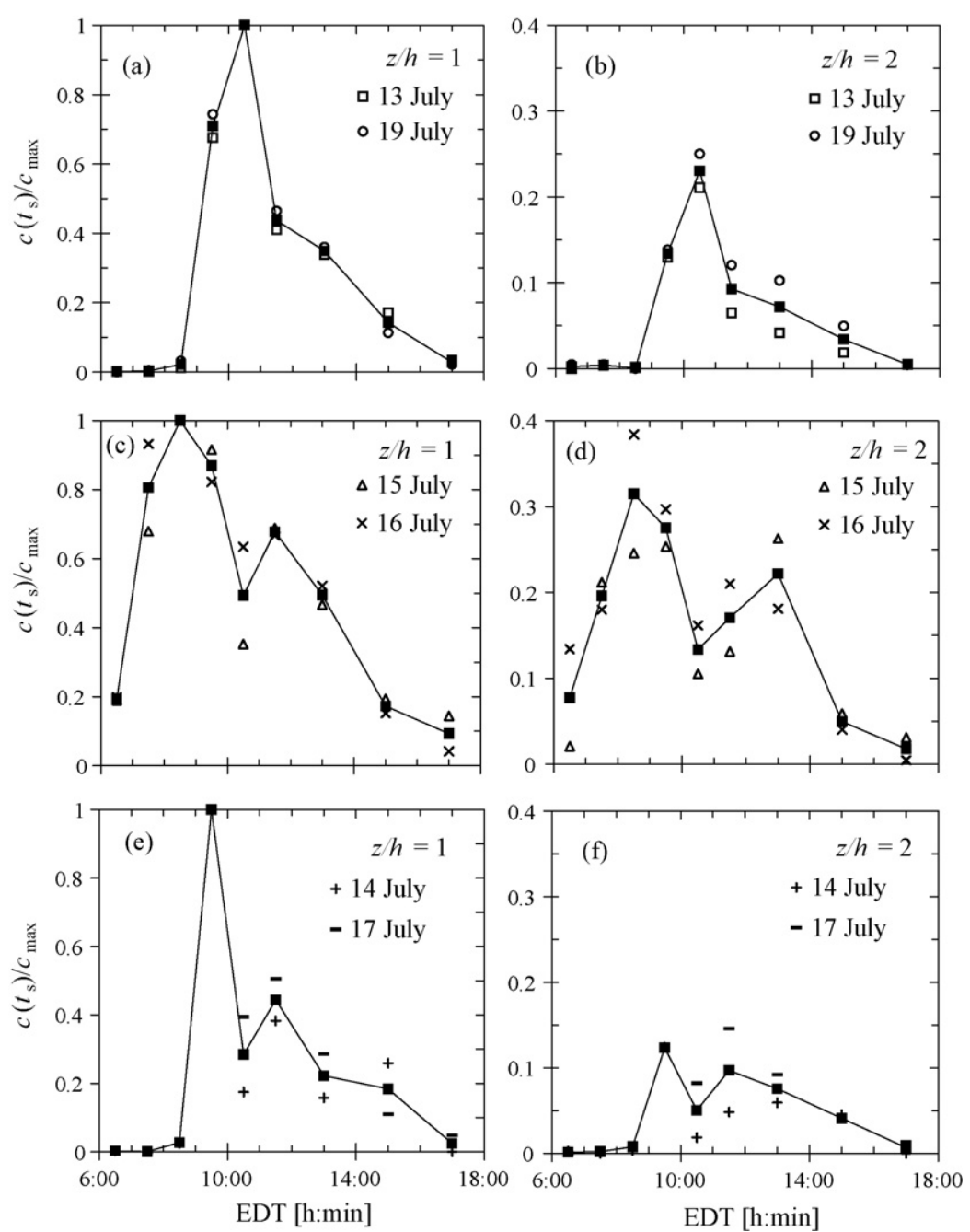

Fig. 6 - Diurnal cycle of normalized corn pollen concentration. Squares are average values (a) and (b) 13 and 19 July; (c) and (d) 15 and 16 July; (e) and (f) 14 and 17 July.

obtained by van Hout and Katz (2004) for hydrated corn pollen grains. The histograms presented in Fig. 7 show that at canopy height, the tail of the pollen size distribution extends to larger diameters than that at $z / h=2$, suggesting that large heavy particles do not reach the highest sampling elevations.

\section{Influence of local meteorological conditions on pollen emission}

In order to investigate the effect of local meteorological conditions on pollen emission, taking into account that the pollen source, i.e. the tassels, are located at the canopy height, the pollen concentration at $z / h=1$ was taken as a surrogate for pollen production (source strength). The diurnal variation of canopy height pollen concentration is depicted in Figs. 8-10 as horizontal bars whose widths indicate the time span over which the data was collected together with temperature $T$, relative humidity $\mathrm{RH}$, solar irradiance $S$, and mean velocity $U$, that were measured by the NOAA weather station.
The temperature range that prevailed during the field studies, $\mathrm{T}=20-30^{\circ} \mathrm{C}$, did not seem to have noticeable effects on the diurnal pollen emission. In addition, no obvious relation between fluctuations in solar irradiance and pollen emission was observed except for day and night cycles, i.e. pollen was only emitted during the daytime. Bi-modal diurnal pollen concentration distributions were observed both at source height as well as higher up, between 14 and 17 July (Figs. 8-10), characterized by a large first peak in pollen concentration early in the morning between 0800 and 0900 EDT or 0900 and 1000 EDT, depending on the day. A second smaller peak was observed later, just before noon between 1100 and 1200 EDT. These measured bi-modal patterns could not be explained by similar bi-modality of $\mathrm{S}, \mathrm{T}, \mathrm{RH}$ or a combination of them. However, on all days that exhibited bimodal pollen concentration patterns, the dip in pollen concentration seemed to coincide with a relatively large decrease ( $30 \%$, emphasized in Figs. 8b, 9 and 10a by a thick line) in mean wind velocity $U$ during the corresponding sampling periods. Note that pollen was sampled at one and two-hourly intervals while the wind conditions changed at 


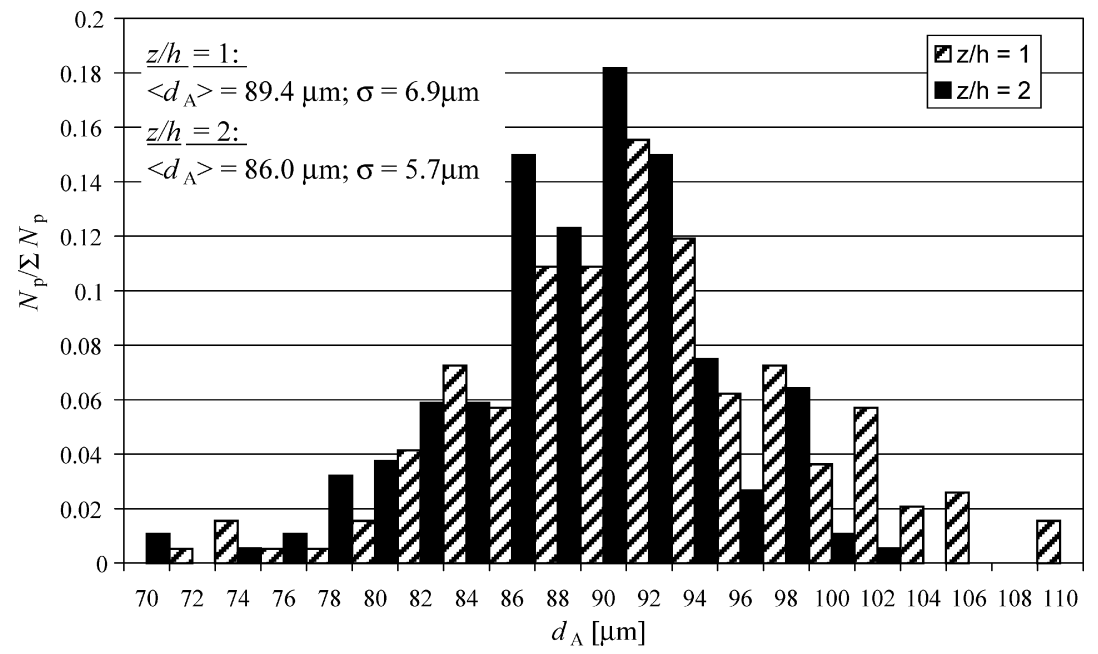

Fig. 7 - Corn pollen size distributions at the highest and lowest sampling elevation between 1100-1200 EDT, 16 July.

smaller time scales (averaged here at 15 min intervals). It would therefore be rather fortuitous to find a correlation between the pollen concentration and wind conditions. However, during the above-mentioned pollen sampling periods for which the concentration reached a minimum, particularly strong and continued decreases in mean velocity occurred. During other pollen sampling periods, decreases in $U$ of similar magnitude can be observed that are counteracted by even larger increases in mean velocity, e.g. Fig. 9a between 0800 and $0900 \mathrm{EDT}$. Since the mean shear rate is intimately tied
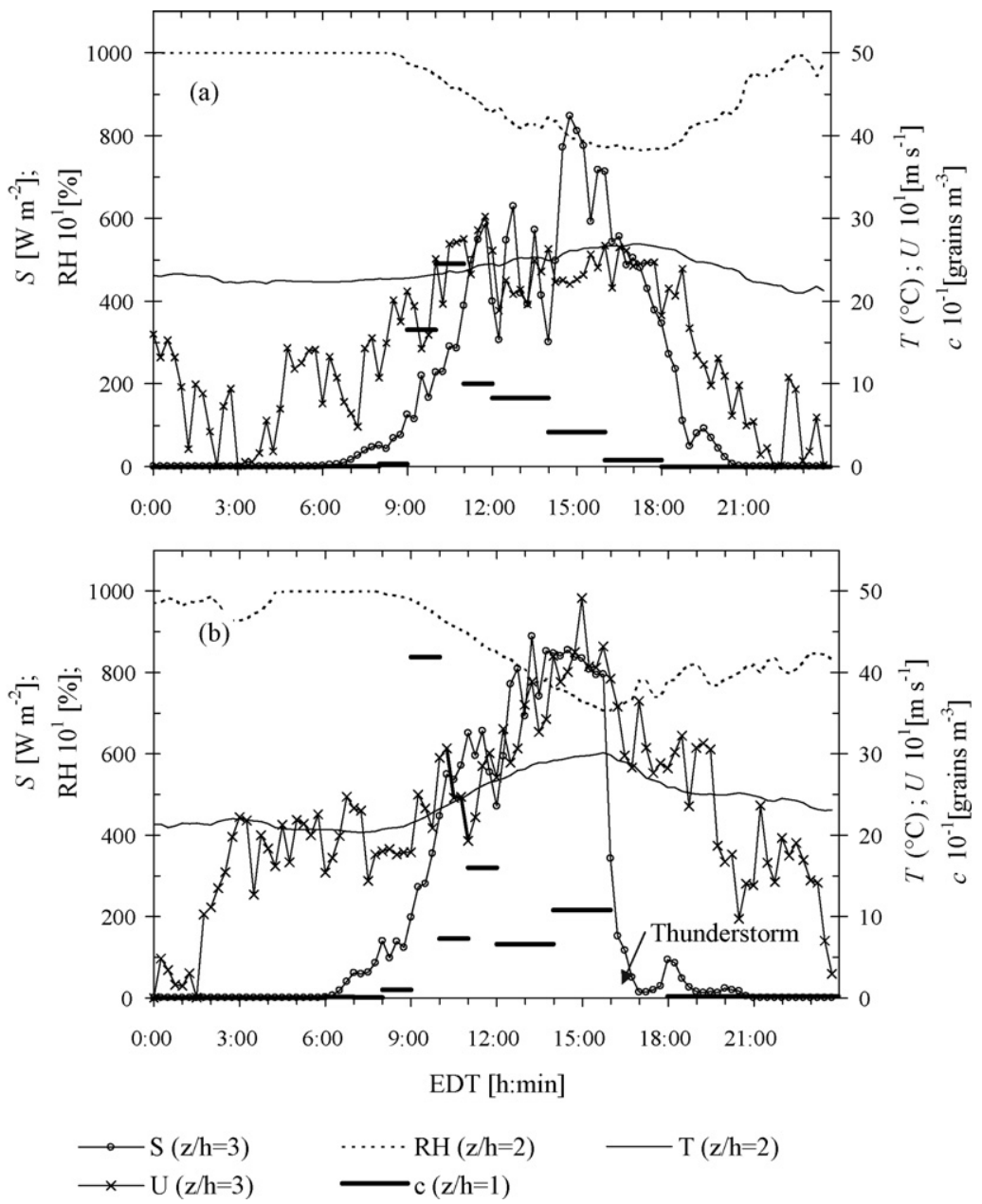

Fig. 8 - Diurnal variations in pollen emission and local 15 min averaged meteorological conditions: (a) 13 July and (b) 14 July. 

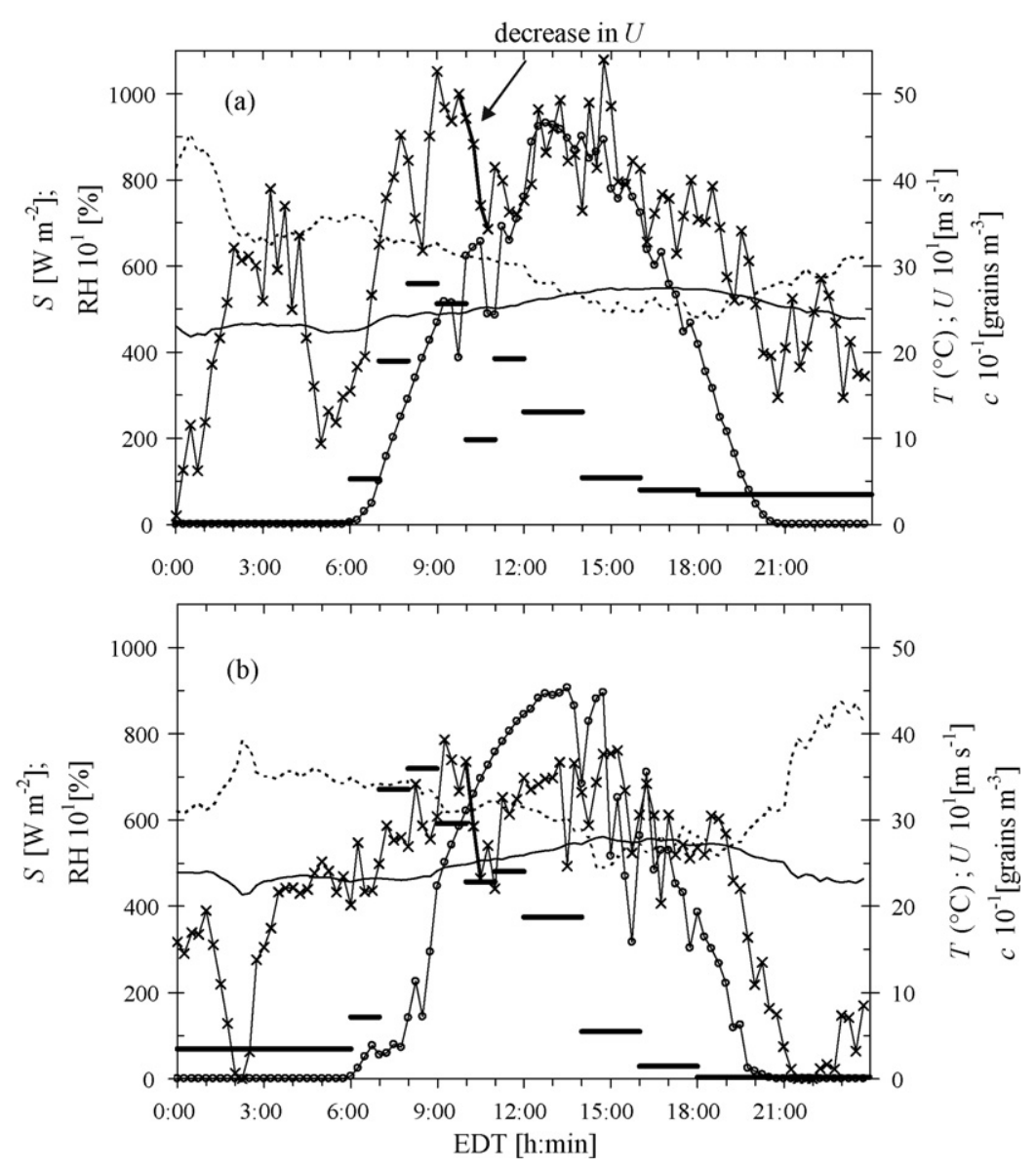

Fig. 9 - Diurnal variations in pollen emission and local 15 min averaged meteorological conditions: (a) 15 July and (b) 16 July. Legend see Fig. 8.

to turbulence generation, the effect of turbulence on the diurnal variation of pollen emission is analyzed in more detail in Section 5.

As discussed in the introduction, pollen emission occurs only when the anther containing the pollen grains has gone through a number of anatomical and morphological changes during maturation (Keijzer et al., 1996). Desiccation then causes the anther to open at its tip (Fig. 1) and pollen is emitted and may be entrained into the atmosphere by mean advection and turbulence. It is evident from Figs. 8-10 that the morning hour at which the first pollen grains were captured by the Rotorod samplers, varied (see also Fig. 5). For example, on 13, 14, 17 and 19 July (Figs. 8 and 10), significant pollen concentrations at canopy height were first measured between 0900 and 1000 EDT whereas on 15 and 16 July (Fig. 9), this occurred earlier between 0600 and 0700 EDT. Jarosz et al. (2005) have shown that in order for the anthers to desiccate, open up and start releasing pollen, the relative humidity has to drop below $100 \%$ corresponding to VPD values ranging between 0.2 and $0.5 \mathrm{kPa}$. On 15 and 16 July (Fig. 9) the relative humidity was rather low during the night, $\mathrm{RH} \approx 70 \%$ corresponding to $0.25 \mathrm{kPa}<\mathrm{VPD}<1.33 \mathrm{kPa}$, and the lack of morning dew enabled the anthers to dehisce immediately at sunrise when VPD values were in excess of $0.8 \mathrm{kPa}$. Consequently, given the fact that the winds were sufficiently strong, pollen grains were captured by the Rotorod samplers between 0600 and 0700 EDT immediately after sunrise. On the other hand, when the air was saturated during the night $(\mathrm{RH}=100 \%)$, on 13, 14 and 19 July (Figs. 8 and 10), airborne pollen was recorded only after the RH dropped below $100 \%$. On these days, the first significant pollen concentrations were measured only between 0900 and 1000 EDT, almost $3 \mathrm{~h}$ after sunrise when VPD values exceeded $0.2 \mathrm{kPa}$, confirming the results of Jarosz et al. (2005). However, it must be noted that during two consecutive nights from 14 to 16 July, VPD values remained high (low $\mathrm{RH}$ ) ranging from 0.25 to $1.33 \mathrm{kPa}$. During the second night from 15 to 16 July (Fig. 9) the average nighttime pollen concentration was 35 grains $\mathrm{m}^{-3}$ while during the first night from 14 to 15 July (Figs. $8 b$ and 9a) no pollen was recorded between 1800 and 0600 EDT. Assuming that the diurnal solar cycle is intricately linked to anther maturation which ultimately dictates the diurnal pollen emission pattern, we speculate that the non-negligible pollen concentration during the second night might be caused by reentrainment of daytime deposited pollen on leaves rather than nighttime pollen emission. However, additional research is needed to verify this. Note that on 14 July at around 1600 EDT, a thunderstorm wetted the corn field presumably preventing pollen emission/re-entrainment during the first night. 

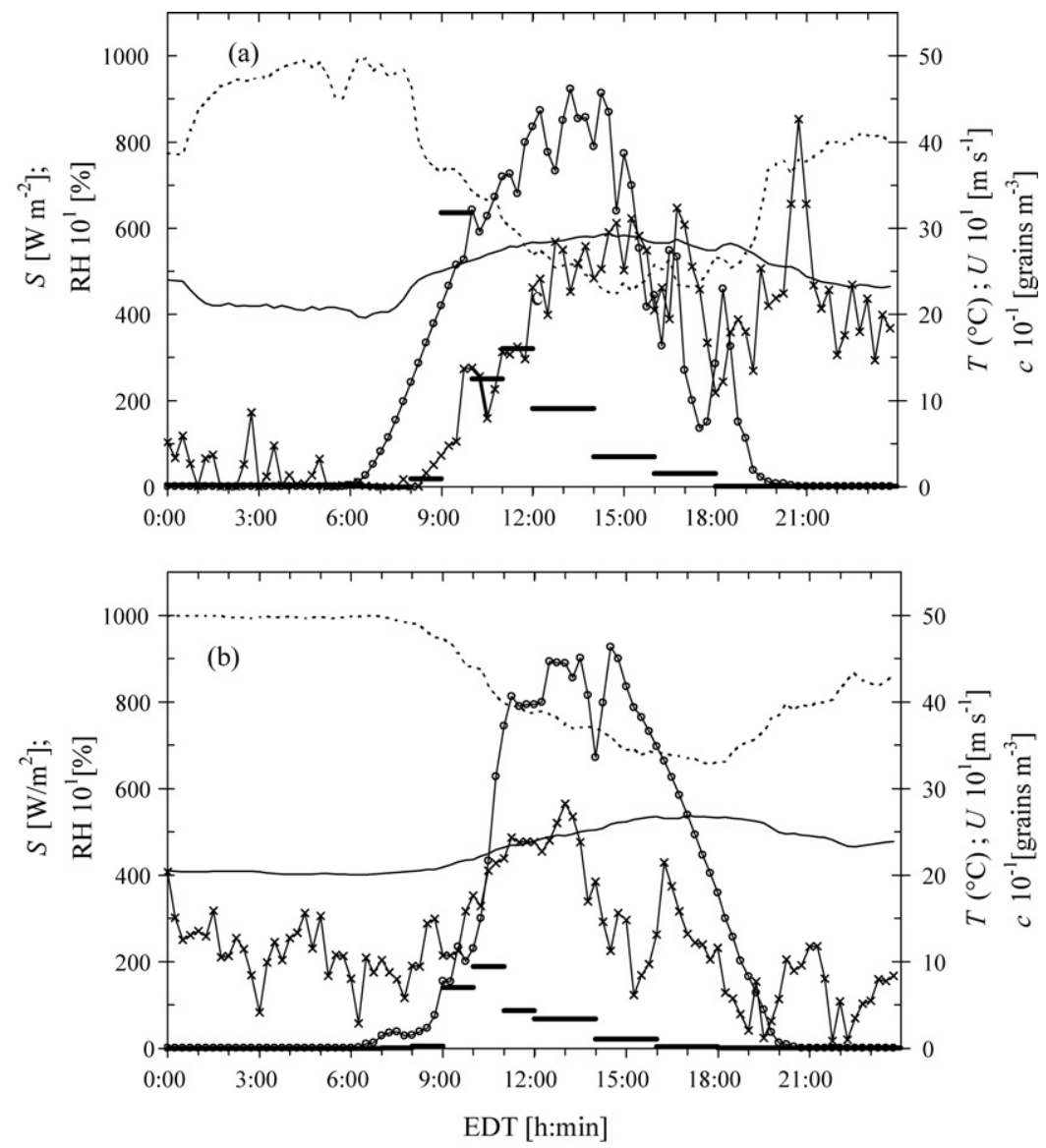

Fig. 10 - Diurnal variations in pollen emission and local $15 \mathrm{~min}$. averaged meteorological conditions: (a) 17 July and (b) 19 July. Legend see Fig. 8.

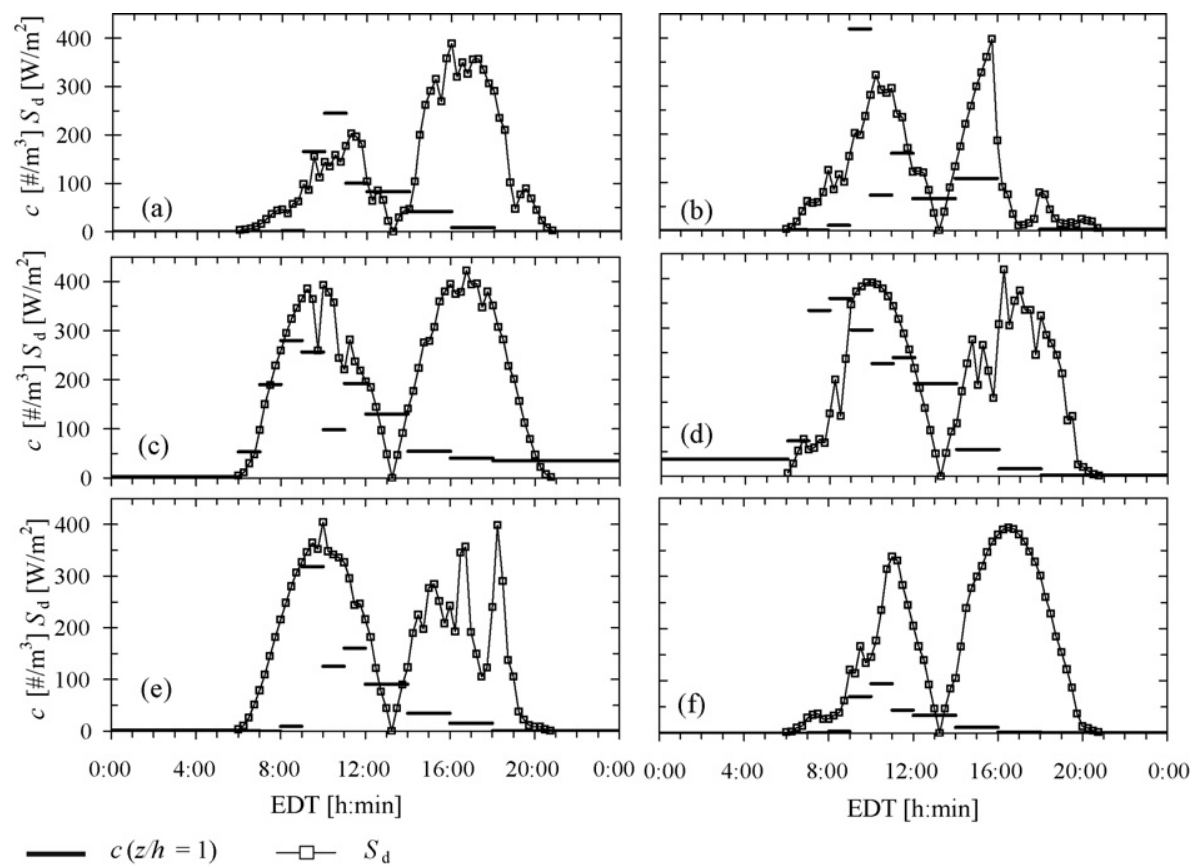

Fig. 11 - Diurnal variations of pollen emission and direct solar irradiance, Eq. (4): (a) 13 July; (b) 14 July; (c) 15 July; (d) 16 July; (e) 17 July; (f) 19 July. 
In addition to low relative humidity, sufficiently strong wind conditions (gusts) are necessary to enable wind dispersal of pollen grains (e.g. Aylor and Parlange, 1975). In the present data, the influence of mean wind conditions is especially clear for 17 July (Fig. 10a). At 0700 EDT, the RH was below 100\% and dropped fast starting at 0800 EDT. However, the first pollen grains were captured only between 0900 and 1000 EDT, during which VPD values increased from 0.84 to $1.08 \mathrm{kPa}$. In this case, there was no wind during early morning hours and the wind started to pick up only around 0830 EDT. Thus, although conditions for anther desiccation were fulfilled, i.e. low $\mathrm{RH}$ (high VPD), winds were not sufficiently strong to transport pollen grains upwards.

As mentioned in the introduction, dehiscence only occurs when the anther is desiccating and an efficient mechanism for drying the anther might be direct radiation. Corn anthers resemble small cylinders similar to pendula hanging from spikelets. When the anthers are sufficiently dry, a pore at the bottom of the anther opens up (Fig. 1). Assuming static anthers that hang down vertically, the rate of direct solar radiant energy to which anthers are exposed can be estimated as

$E_{\mathrm{d}}(t, \gamma) \approx S(t) \ell D \cos \gamma$

where $\gamma$ is the solar angle, the subscript ' $d$ ' denotes "direct", $t$ is the time in the diurnal cycle, $\ell$ is the length of the anther and $D$ its diameter. In this simplified model, we account only for the irradiance on the projected area of the cylindrical body of the anther and neglect the relatively small circular cross-section of its base. Further, we assume that at solar noon, $E_{d}\left(\gamma=90^{\circ}\right)=0$, since the solar irradiance is parallel to the axis of the cylindrical anther. The rate of direct solar energy exposure per unit area of the anther surface is then defined as

$S_{\mathrm{d}}(t, \gamma) \approx \frac{E_{\mathrm{d}}(t, \gamma)}{\ell D}=\mathrm{S}(\mathrm{t}) \cos \gamma$

The diurnal variations of $S_{d}$ are plotted in Fig. 11 together with the measured diurnal variation of pollen concentrations at canopy height from 13 to 17 July and 19 July. Clearly, in all cases, the peak value of $S_{d}$ occurs shortly after the first large peak in pollen concentration suggesting that direct energy absorption is an important mechanism responsible for drying of the anther. There is no indication that the second peak of the bi-modal pollen concentration profiles is related to $S_{d}$. There is also no relationship between direct absorption of solar irradiance and pollen emission during the afternoon hours.

\section{Influence of turbulence on pollen emission}

In still air, corn pollen settles at a terminal velocity that can be calculated using Stokes law (Clift et al., 1978):

$w_{\mathrm{s}}^{\mathrm{t}}=\frac{\left(\rho_{\mathrm{p}}-\rho_{\mathrm{a}}\right) g d_{\mathrm{A}}^{2}}{18 \mu_{\mathrm{a}}}=0.27 \mathrm{~m} \mathrm{~s}^{-1}$ where $g$ is the gravitational constant, $\mu$ is the dynamic viscosity, $\rho$ is the density and the subscripts ' $p$ ' and ' $a$ ' denote "pollen" and "air", respectively. The corn pollen density has been measured by van Hout and Katz (2004), giving $\rho_{\mathrm{p}}=1.14 \times 10^{3} \pm 0.05 \times 10^{3} \mathrm{~kg} \mathrm{~m}^{-3}$. Eq. (5) is only valid for low particle Reynolds numbers, $R e_{\mathrm{p}}=\rho_{\mathrm{a}}\left|U_{\mathrm{r}}\right| d_{\mathrm{A}} / \mu_{\mathrm{a}}$, where $U_{\mathrm{r}}$ is the vector of relative velocity between pollen and air. Assuming that the magnitude of the relative velocity between pollen and air does not substantially exceed the settling velocity in still air, $w_{\mathrm{s}}^{\mathrm{t}}$ (note: turbulence increases the settling velocity of heavy particles but not by an order of magnitude e.g. Wang and Maxey, 1993; Aliseda et al., 2002; Yang and Shy, 2005; Bosse et al., 2006), the particle Reynolds number is, $R e_{\mathrm{p}}=1.6$. At this level the characteristic error involved in using the drag force based on Stokes flow is approximately $20 \%$ (e.g. White, 1991).

In a turbulent flow field, we can associate the force for keeping pollen suspended into the atmosphere with wallnormal turbulent velocity fluctuations. Simplistically, i.e. if particle inertia is neglected, upward directed turbulent fluctuating velocities in excess of the particle's settling velocity would lift the particle upwards provided their strength exceeds a minimum threshold imposed by the pollen settling velocity. Since the mean settling velocity of corn pollen in turbulent flows was not measured, the quiescent air value is used as a reference, $w_{\mathrm{s}}^{\mathrm{t}}=0.27 \mathrm{~m} \mathrm{~s}^{-1}$. However, the vertical velocity fluctuations are time dependent and particle inertia may become important, as one would conclude by examining the Stokes number, St. The Stokes number is defined as the ratio between the particle response time, $\tau_{\mathrm{p}}$, and a characteristic time scale of the flow, e.g. the Kolmogorov time scale, $\tau_{\mathrm{k}} \equiv(\nu / \varepsilon)^{1 / 2}$, where $\varepsilon$ is the dissipation rate of turbulent kinetic energy and $v$ is the kinematic viscosity of air. The pollen response time is typically estimated as the Stokes time $\tau_{\mathrm{p}} \cong\left(2 \rho_{\mathrm{p}}\left(d_{\mathrm{A}} / 2\right)^{2}\right) / 9 \mu_{\mathrm{a}}$, which is the time required for the pollen to reach $63 \%$ of its terminal velocity in still air assuming Stokes flow drag (Clift et al., 1978). For mean streamwise velocities ranging between 1 and $2 \mathrm{~m} \mathrm{~s}^{-1}$, typical dissipation rates around corn canopy height are $\varepsilon \approx 0.1-0.2 \mathrm{~m}^{2} \mathrm{~s}^{-3}$ (Brunet et al., 1994; van Hout et al., 2007). Thus, $\mathrm{St}=\tau_{\mathrm{p}} / \tau_{\mathrm{k}} \approx 3-4$, indicating that the particle response is slower but of the same order as the Kolmogorov time scale. Thus, although inertia plays a significant role in corn pollen dynamics, the pollen grains should still respond to a substantial fraction of turbulent fluctuations (e.g. Wang and Maxey, 1993), especially the larger ones, whose time scales typically extend to orders of magnitude larger than the Kolmogorov time scale (Shaw et al., 1974; Wilson et al., 1982; van Hout et al., 2007).

The turbulent flow field characteristics are investigated using the data of the sonic anemometers (available from 16 July onwards) $)^{2}$ mounted at $z / h=1$ and 1.5 . The root mean square (rms) values of vertical velocity fluctuations, $\sigma_{\mathrm{w}}$, are shown in Fig. 12 together with the diurnal distribution of corn pollen concentration for $16,17,19$ and 20 July at $z / h=1$ and 2 . Note that instantaneous values of vertical velocity fluctuations reach much higher levels than the rms values. The dashed, horizontal line corresponds to the Stokes settling velocity of corn pollen in still air (Eq. (5)). Comparing the times

${ }^{2}$ Earlier sonic data was lost in the field due to a hard disk failure. 

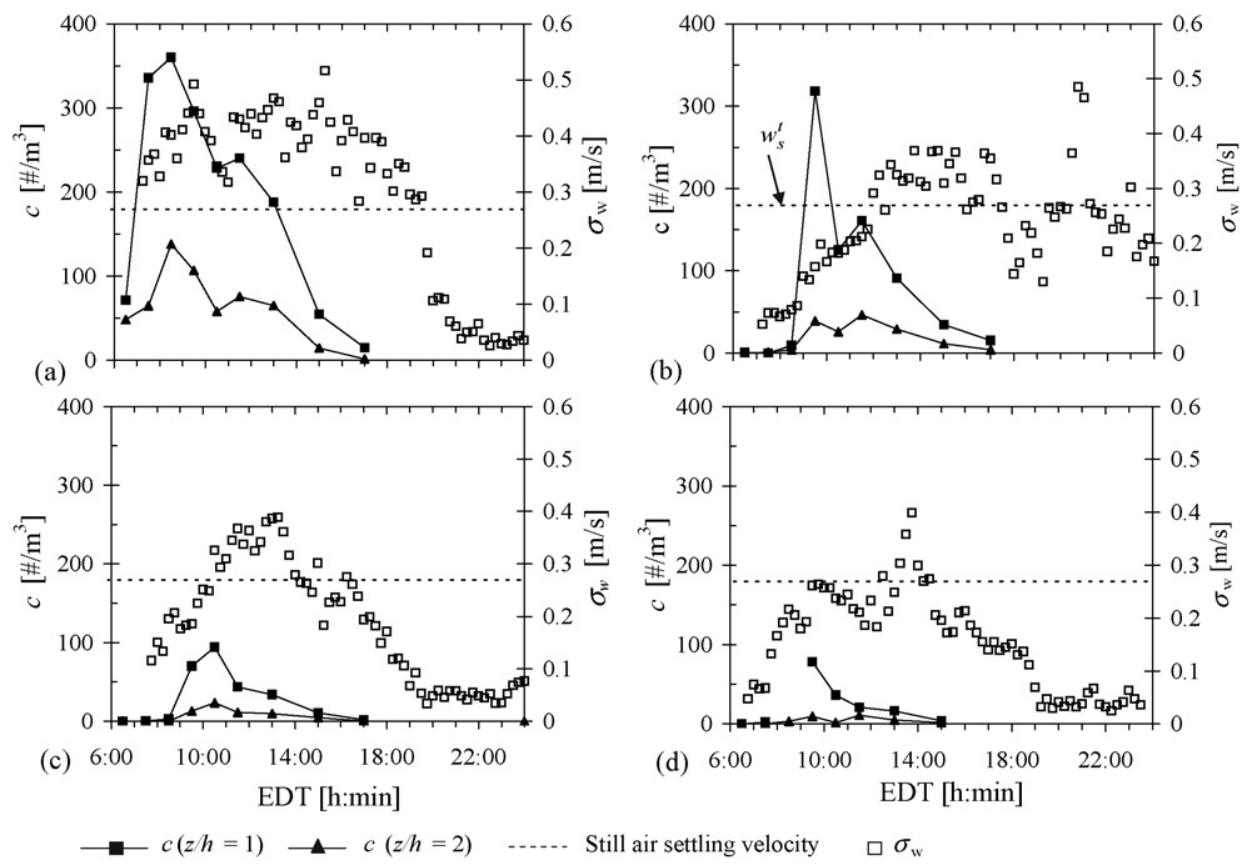

Fig. 12 - Diurnal patterns of $\sigma_{\mathrm{w}}$ at canopy height and pollen concentration: (a) $16 \mathrm{July}$; (b) 17 July; (c) 19 July; (d) 20 July.

that significant pollen concentrations were recorded to the magnitudes of the rms values, Fig. 12 suggests that $\sigma_{\mathrm{w}}$ was at least larger than $0.15-0.2 \mathrm{~m} \mathrm{~s}^{-1}$ (especially clear in Fig. 12b, during the morning hours of 17 July) when pollen was airborne. With the exception of 17 July, the magnitude of $\sigma_{\mathrm{w}}$ drops to almost zero close to sunset, and no pollen were captured by the Rotorods after sunset. On 17 July, after sunset, $\sigma_{\mathrm{w}}$ remained relatively high and exceeded $0.15-0.2 \mathrm{~m} \mathrm{~s}^{-1}$ while at the same time the relative humidity was well below $100 \%$ (Fig. 10a), thereby setting the right conditions for anther dehiscence and pollen emission/dispersal. However, also in this case no airborne pollen was sampled. Apparently, the corn anthers did not emit any pollen, raising questions as to how anther maturation is linked to the diurnal solar cycle.

The turbulence level affected the upward transport of pollen (e.g. see the theoretical profiles proposed by Chamecki et al.,

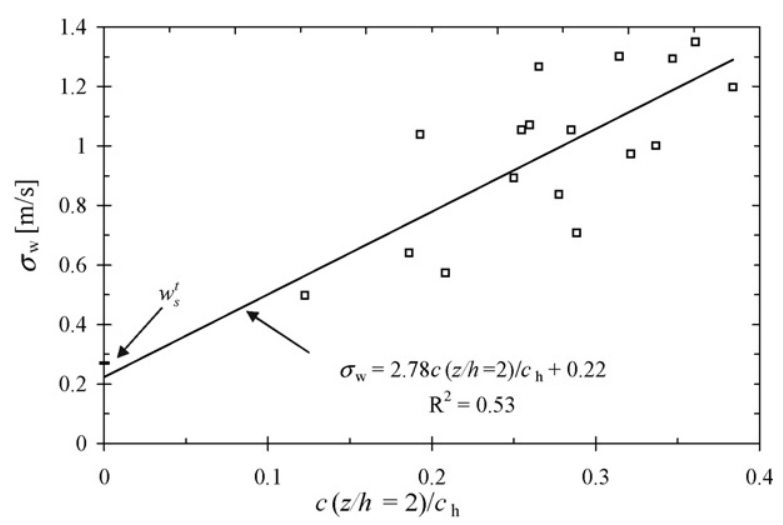

Fig. 13 - Rms of vertical velocity fluctuations versus the fraction of pollen transported upwards from canopy height, 16, 17 and 19 July.
2007). For example, on 17 July from 0900 to 1000 EDT, high pollen concentrations were sampled at $\mathrm{z} / \mathrm{h}=1$ while $\sigma_{\mathrm{w}}$ was relatively low $0.1-0.2 \mathrm{~m} \mathrm{~s}^{-1}$, close to the presumed threshold level of becoming airborne. Such a low level would limit the vertical upward transport of the pollen grains as indicated by a low ratio of $c(z / h=2) / c_{h}$. As the wind picked up and the magnitude of $\sigma_{\mathrm{w}}$ increased, the fraction of emitted pollen at canopy height that reached twice this height, $c(z / h=2) / c_{h}$, increased. The scaling of $c(z / h=2) / c_{h}$ with $\sigma_{\mathrm{w}}$ is shown in Fig. 13. Only data points on 16, 17 and 19 July when $c_{h}$ exceeded 10 grains $\mathrm{m}^{-3}$ are plotted. Although there is significant scatter, the data indicate that the ratio $c(z / h=2) / c_{h}$ increases as $\sigma_{w}$ increases. Furthermore, a least square linear fit to the data indicates that no pollen is transported upwards at a threshold value of $\sigma_{\mathrm{w}}=0.22 \mathrm{~m} \mathrm{~s}^{-1}$ which is of the same order as the pollen settling velocity in quiescent air, $w_{\mathrm{s}}^{\mathrm{t}}=0.27 \mathrm{~m} \mathrm{~s}^{-1}$, Eq. (5).

\subsection{Upward pollen transport by ejections}

The turbulent boundary layer above and within a corn canopy is dominated by a succession of sweep and ejection events, the former being a fast downward flow and the latter a slow upward flow (see e.g. Shaw et al., 1983). These events are the primary mechanisms for momentum and scalar exchange with the atmospheric boundary layer above the canopy. In addition, it has been shown by direct numerical simulations (DNS, e.g. Soldati, 2005) that the ejection-sweep cycles are instrumental in the entrainment, dispersal and deposition of heavy particles. Ejection-sweep cycles in corn canopy flows have been investigated by Shaw et al. (1983) and by Zhu et al. (2006, 2007a) using a technique called Quadrant-Hole (Q-H) analysis (Willmarth and Lu, 1972). This analysis was applied to the sonic anemometers' data using increasing threshold values, the lowest being $|u w|=0.01 \mathrm{~m}^{2} \mathrm{~s}^{-2}$ which corresponds 


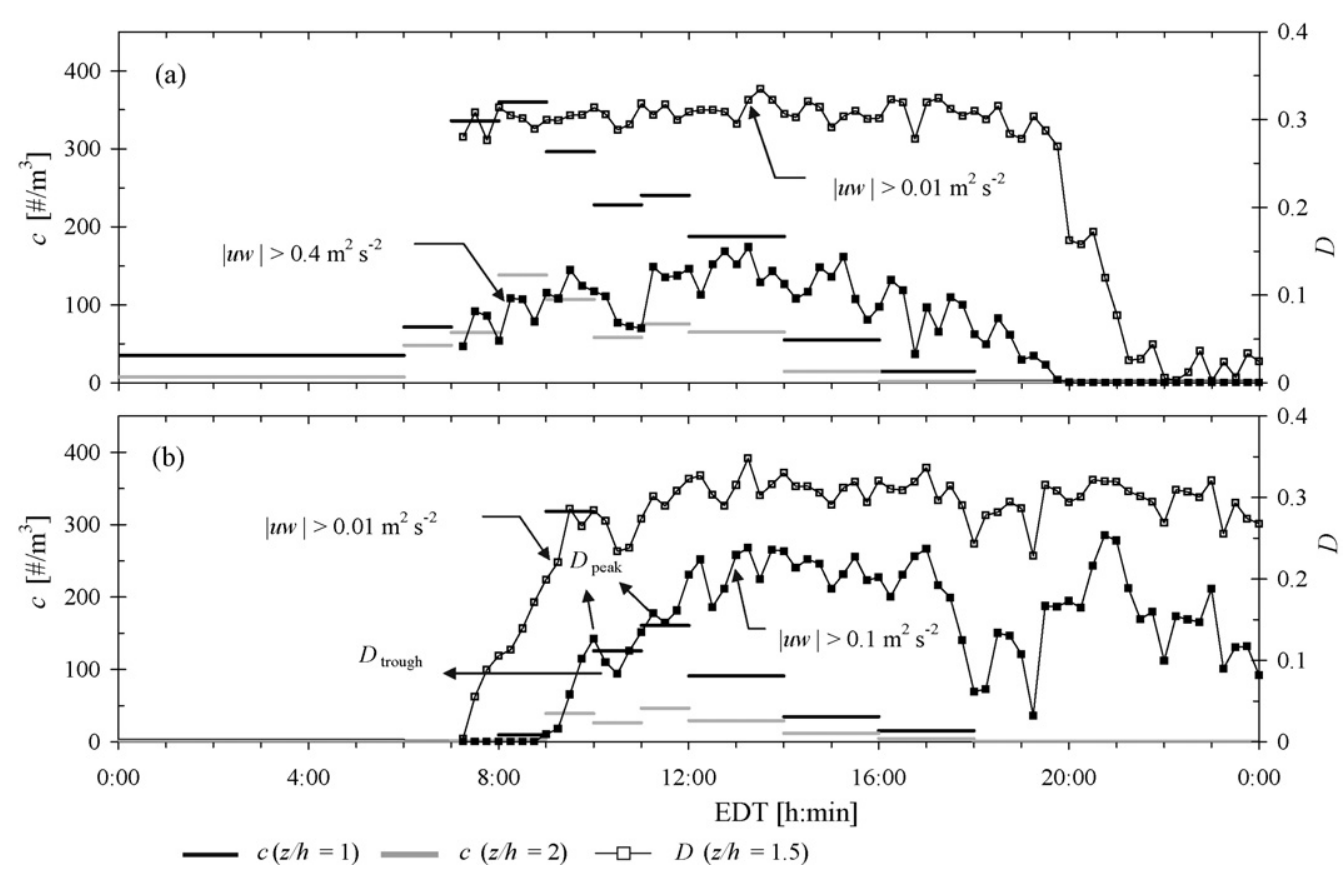

Fig. 14 - Diurnal variation of pollen concentration and duration fractions of Q2 events thresholded on $\mid$ uw|: (a) 16 July and (b) 17 July.

to $\sigma_{\mathrm{w}} \approx 0.12 \mathrm{~m} \mathrm{~s}^{-1}$ since $\sigma_{\mathrm{w}} / \mathrm{u}_{*} \approx 1.2$ following Monin-Obukhov scaling (Kaimal and Finnigan, 1994) and $u_{*} /\langle\sqrt{|u w|}\rangle \approx 1$. Quadrants associated with upward vertical velocity fluctuations are quadrants 1 and 2 (Q1 and Q2), "outward interaction" and "ejection", respectively. Since the measured duration fractions of Q1 events were less than half of those of ejections (see also Shaw et al., 1983; Zhu et al., 2006, 2007a,b) and displayed similar diurnal patterns as Q2 duration fractions, only the duration fractions of ejections are presented.

The duration fraction, $D$, defined as the ratio between the cumulative time duration of events exceeding the threshold value and the total sampling time, together with the pollen concentrations at $z / h=1$ and 2, are plotted in Fig. 14 for 16 and 17 July. The duration fractions of ejections at $z / h=1.5$, conditionally sampled at different thresholds as indicated in Fig. 14, are presented as open and closed squares. The diurnal variation of the thresholded duration fraction at canopy height was similar to that at $z / h=1.5$ and is not shown. The diurnal variation of $D$ during 16 July at the lowest threshold value $|u w|>0.01 \mathrm{~m}^{2} \mathrm{~s}^{-2}$, presented in Fig. 14a, shows a more or less constant value of about $D \approx 0.3$ between 0700 and 1900 EDT. At first, fluctuations in the duration fraction do not seem to be related to variations in pollen concentration. However, when the threshold value is increased to $|u w|>0.4 \mathrm{~m}^{2} \mathrm{~s}^{-2}$ (closed symbols, "extreme" events with reduced values of $D$ ), fluctuations become much larger. It can now be clearly discerned that during the sampling period 0900-1000 EDT, just before the pollen concentration reaches a minimum, the "extreme" event duration fraction peaks $(D=0.13$ at 0930 EDT) and then decreases to a minimum ( $D=0.06$ at 1000 EDT) during the same sampling period that pollen concentrations are minimal. Subsequently, the duration fraction rises sharply again to a value of $D=0.13$ at 1015 EDT.
The diurnal variation of the ejection duration fraction on 17 July (Fig. 14b) shows a similar pattern as discussed above, already emerging at the lowest threshold level. At this threshold, $|u w|=0.01 \mathrm{~m}^{2} \mathrm{~s}^{-2}$ (open symbols), the ejection duration fraction starts to rise sharply just after 0715 EDT and peaks during the first sampling period that has a significant pollen concentration (0900-1000 EDT). The duration fraction is then reduced again to a minimum coinciding with the sampling period of minimum pollen concentration (10001100 EDT) after which the duration fraction as well as the pollen concentration increases again. This description remains more or less the same when the threshold value is 10 -fold increased to $|u w|=0.1 \mathrm{~m}^{2} \mathrm{~s}^{-2}$ (closed squares). Events of this magnitude occur only on 17 July after 0915 EDT, the diurnal variation being similar to the one described for the lower threshold value albeit with lower values of $D$. Although there are fluctuations in duration fraction of similar magnitude during the afternoon, no synchronized fluctuations in pollen concentration are observed. This may be caused by the two-hourly pollen sampling periods during the afternoon that act as a low-pass filter.

The relative reduction in duration fraction $D_{\text {peak }} / D_{\text {trough }}$ at $z / h=1.5$ as a function of the threshold value $|u w|$ is depicted in Fig. 15 for 16 and 17 July. $D_{\text {trough }}$ is the minimum duration fraction during the sampling period of minimum pollen concentration (i.e. 1000-1100 EDT, see Fig. 14b) while $D_{\text {peak }}$ is the maximum duration fraction in the pollen sampling period prior to that (0900-1000 EDT, "decrease") or just after it ("increase", 1100-1200 EDT, see Fig. 14b). Fig. 15 shows that at the lowest threshold value, $D_{\text {peak }} / D_{\text {trough }} \approx 1.1$ for 16 July and 1.3 for 17 July. As the threshold is increased, $D_{\text {peak }} / D_{\text {trough }}$ increases for both days, the fastest for 17 July as $D_{\text {trough }}$ is strongly reduced and becomes near zero at the higher 


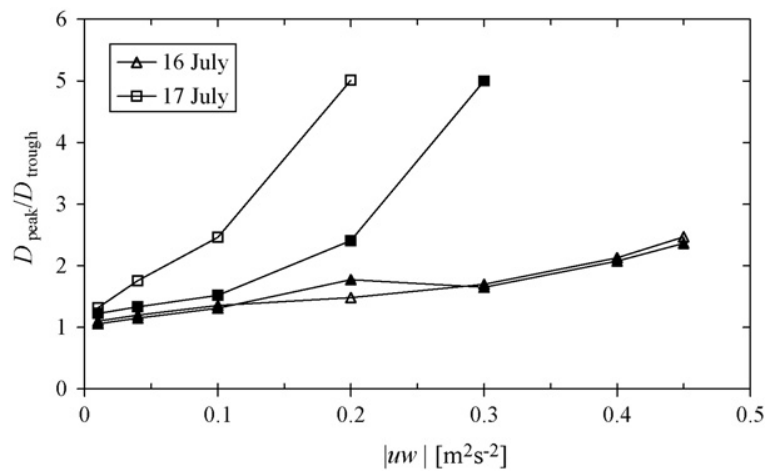

Fig. 15 - Duration fraction ratio as a function of threshold level $|u w|$. Open symbols: "increase"; closed symbols: "decrease".

thresholds. For 16 July, at the highest threshold value $|u w|>0.45, D_{\text {peak }} / D_{\text {trough }} \approx 2.4$. Thus, Fig. 15 indicates that relative to the neighboring pollen sampling periods, "extreme" ejections (high thresholds) occur increasingly less as the threshold value is raised during periods of minimum pollen concentration. Thus, "extreme" events may be instrumental as an upward pollen transport mechanism as indicated by DNS (Soldati, 2005). However, since the here presented synchronicity between turbulence and pollen concentration is based on measurements made during only 2 days, one should be careful with its interpretation.

\section{Summary and conclusions}

The diurnal patterns of corn pollen concentration at four different heights above a pollinating corn field were measured during 10 days together with relevant meteorological and turbulence parameters. Pollen concentrations decreased rapidly with elevation, e.g. at twice the canopy height they were reduced to about $30 \%$ of those observed at canopy height. Diurnal cycles of atmospheric pollen concentration were characterized by an initial emission of pollen after sunrise, with peak values during the morning hours and decaying values during the afternoons. No significant pollen concentrations were measured starting $2 \mathrm{~h}$ before sunset until the following morning at sunrise. Presumably the diurnal solar cycle is intimately tied to anther maturation which ultimately governs pollen emission. The hour at which the first pollen grains were entrained into the atmosphere varied from dayto-day, depending strongly on the relative humidity and related vapor pressure deficit values as well as on the prevailing wind speeds. Low relative humidity during the night, i.e. the absence of dew, caused pollen emission immediately at sunrise consistent with previous measurements performed by Jarosz et al. (2005). On four consecutive days, daily pollen concentration patterns were bi-modal during the morning hours while on other days only a single peak distribution was observed. Diurnal, bi-modal corn pollen distributions were previously reported by Flottum et al. (1984) without providing an explanation for them. Our attempts to relate the bi-modal diurnal distributions to changes in temperature and relative humidity failed. However, in our case, the timing of the first pollen concentration peak agreed well with that of a peak in direct solar radiant energy on the anther when modeled as a vertically suspended cylinder. This observation supported our hypothesis that solar irradiance may be a driving force behind corn anther desiccation and dehiscence. For days on which bi-modal pollen concentration distributions were measured, the data further suggested that the dip in pollen concentration after the first peak was synchronized with a large decrease ( 30\%) in mean velocity.

The pollen concentration data were further analyzed in relation to the turbulent flow field measured by 3D sonic anemometers. Significant quantities of pollen were found to be airborne at twice the canopy height when the rms values of vertical velocity fluctuations, $\sigma_{\mathrm{w}}$, exceeded $0.15-0.2 \mathrm{~m} \mathrm{~s}^{-1}$ which was of the same order as the estimated magnitude of the still air settling velocity of spherical particles with size and density of corn pollen. The fraction of pollen transported upwards from canopy height to twice this height, increased with increasing $\sigma_{\mathrm{w}}$. The influence of turbulent events that are typically associated with large coherent structures in the canopy boundary layer (e.g. Finnigan, 2000; Zhu et al., 2007b), was examined by applying Quadrant-Hole analysis to the sonic anemometer's data sets. In particular, the effect of turbulent events with positive vertical velocity fluctuations, ejections being the prominent phenomenon, was related to the fraction of pollen transported upwards from canopy height. For the 2 days that turbulence data were available, the analysis showed that during morning hours, periods with high duration fraction of strong upward motions ("ejections") coincided with those of high pollen concentrations, and periods with decreased duration fraction had lower concentrations. These results suggest that the measured diurnal bi-modal pollen concentration patterns were associated with a lull in the duration of upward motions, especially evident in the duration fraction of strong ejection events. Furthermore, diurnal patterns of the fraction of pollen that reach high elevations, i.e. $c(z / h=2) / c_{h}$ followed the same trends as ejection duration fractions, indicating the important effect of large coherent structures on pollen dispersal.

\section{Acknowledgements}

We are grateful to the staff at the Wye Research and Education Center of the University of Maryland, in particular to Mike Embry and Mary Catherine Morissey for their assistance in finding a proper location and in supplying some of the meteorological data. We furthermore acknowledge the help of Randy Meyer of NOAA for supplying us with information regarding the weather station and are grateful for the assistance of Joe Smith and Chad Higgins in the field set-up. Pollen counts were made by Joe Smith and Sruti Sathyanadhan. We would also like to thank Charles Meneveau for his input during discussions of this project. This research was funded by the Biocomplexity Program of the National Science Foundation under grant 0119903. 


\section{R E F E R E N C E S}

Aliseda, A., Cartellier, A., Hainaux, F., Lasheras, J.C., 2002. Effect of preferential concentration on the settling velocity of heavy particles in homogeneous isotropic turbulence. J. Fluid Mech. 468, 77-105.

Aylor, D.E., 2005. Quantifying maize pollen movement in a maize canopy. Agric. For. Meteorol. 131, 247-256.

Aylor, D.E., Schultes, N.P., Shields, E.J., 2003. An aerobiological framework for assessing cross-pollination in maize. Agric. For. Meteorol. 119, 111-129.

Aylor, D.E., Parlange, J.-Y., 1975. Ventilation required to entrain small particles from leaves. Plant Physiol. 5, 97-99.

Bonner, L.J., Dickinson, H.G., 1990. Anther dehiscence in Lycopersicon esculentum. II. Water relations. New Phytol. 115, 367-375.

Bosse, T., Kleiser, L., Meiburg, E., 2006. Small particles in homogeneous turbulence: settling velocity enhancement by two-way coupling. Phys. Fluids 18 doi:10.1063/1.2166456.

Brunet, Y., Finnigan, J.J., Raupach, M.R., 1994. A wind tunnel study of air flow in waving wheat: single point velocity statistics. Boundary-Layer Meteorol. 70, 95-132.

Chamecki, M., van Hout, R., Meneveau, C., Parlange, M.B., 2007. Particle concentration profiles in the neutral and stratified atmospheric boundary layer. Boundary-Layer Meteorol. 125, 25-38 doi:10.1007/s10546-007-9194-5.

Clift, R., Grace, J.R., Weber, M.E., 1978. Bubbles, Drops and Particles. Academic Press Inc., 380 p.

Finnigan, J.J., 2000. Turbulence in plant canopies. Annu. Rev. Fluid Mech. 32, 519-571.

Frenz, D.A., 2000. The effect of windspeed on pollen and spore counts with the Rotorod sampler and Burkard spore trap. Asthma Immunol. 85, 392-394.

Flottum, P.K., Robacker, D.C., Erickson Jr., E.H., 1984. A quantitative sampling method for airborne sweet corn pollen under field conditions. Crop Sci. 24, 375-377.

Galán, C., Alcázar, P., Cariños, Garcia, H., Domínguez-Vilches, E., 2000. Meteorological factors affecting daily urticaceae pollen counts. Int. J. Biometeorol. 43, 191-195.

Heslop-Harrison, J.S., Heslop-Harrison, Y., Reger, B.J., 1987. Anther filament extension in Lilium: potassium ion movement and some anatomical features. Ann. Bot-London 59, 505-515.

Honnay, O., Jacquemyn, H., Bossuyt, B., Hermy, M., 2005. Forest fragmentation effects on patch occupancy and population viability of herbaceous plant species. New Phytol. 166, 723-736.

Jackson, S.T., Lyford, M.E., 1999. Pollen dispersal models in quaternary plant ecology: assumptions, parameters and prescriptions. Bot. Rev. 65, 39-75.

Jarosz, N., Durand, B., McCartney, A., Foueillassar, X., Huber, L., 2003. Field measurements of airborne concentration and deposition rate of maize pollen. Agric. For. Meteorol. 119, 37-51.

Jarosz, N., Loubet, B., Huber, L., 2004. Modelling airborne concentration and deposition rate of maize pollen. Atmos. Environ. 38, 5555-5566.

Jarosz, N., Loubet, B., Durand, B., Foueillassar, X., Huber, L., 2005. Variations in maize pollen emission and deposition in relation to microclimate. Environ. Sci. Technol. 39, 4377-4384.

Kaimal, J.C., Finnigan, J.J., 1994. Atmospheric Boundary Layer Flows. Oxford University Press, $288 \mathrm{p}$.

Keijzer, C.J., Leferink-Ten Klooster, H.B., Reinders, M.C., 1996. The mechanics of the grass flower: anther dehiscence and pollen shedding in maize. Ann. Bot-London 78, 15-21.
Klein, E.K., Lavigne, C., Foueillassar, X., Gouyon, P.H., Larédo, C., 2003. Corn pollen dispersal: quasi-mechanistic models and field experiments. Ecol. Monogr. 73, 131-150.

Loos, C., Seppelt, R., Meier-Bethke, S., Schiemann, J., Richter, O., 2003. Spatially explicit modeling of transgenic maize pollen dispersal and cross-pollination. J. Theor. Biol. 225, 241-255.

May, K.R., Pomeroy, N.P., Hibbs, S., 1976. Sampling techniques for large windborne particles. J. Aerosol Sci. 7, 53-62.

McDonald, M.S., 1980. Correlation of air-borne grass pollen levels with meteorological data. Grana 19, 53-56.

Messeguer, J., Foghre, C., Guiderdoni, E., Marfà, V., Català, M.M., Baldi, G., Melé, E., 2001. Field assessments of gene flow from transgenic to cultivated rice (Oriva sativa L.) using a herbicide resistance gene as tracer marker. Theor. Appl. Genet. 103, 1151-1159.

Mullins, J., Emberlin, J., 1997. Sampling pollens. J. Aerosol Sci. 28, 365-370.

Ogden, E.C., Hayes, J.V., Raynor, G.S., 1969. Diurnal patterns of pollen emission in Ambrosia, Phleum, Zea, and Ricinus. Am. J. Bot. 56, 16-21.

Raynor, G.S., Ogden, E.C., Hayes, J.V., 1972. Dispersion and deposition of corn pollen from experimental sources. Agron. J. 64, 420-427.

Shaw, R.H., Den Hartog, G., King, K.M., Thurtell, G.W., 1974. Measurements of mean wind flow and three-dimensional turbulence intensity within a mature corn canopy. Agric. Meteor. 13, 419-425.

Shaw, R.H., Tavangar, J., Ward, D.P., 1983. Structure of the Reynolds stress in a canopy layer. J. Clim. Appl. Meteorol. 22, 1922-1931.

Soldati, A., 2005. Particles turbulence interactions in boundary layers. Z. Angew. Math. Mech. 85, 683-699.

van Hout, R., Katz, J., 2004. A method for measuring the density of irregularly shaped biological aerosols such as pollen. J. Aerosol Sci. 35, 1369-1384.

van Hout, R., Zhu, W., Luznik, L., Katz, J., Kleissl, J., Parlange, M., 2007. PIV measurements in the atmospheric boundary layer within and above a mature corn canopy. Part I. Statistics and energy flux. J. Atmos. Sci. 64, 2805-2824 doi:10.1175/ JAS3989.1.

Wang, L.P., Maxey, M.R., 1993. Settling velocity and concentration distribution of heavy particles in homogeneous isotropic turbulence. J. Fluid Mech. 256, 27-68.

Watrud, L.S., Henry Lee, E., Fairbrother, A., Burdick, C., Reichman, J.R., Bollman, M., Storm, M., King, G., Van de Water, P.K., 2004. Evidence for landscape-level, pollenmediated gene flow from genetically modified creeping bentgrass with CP4 EPSPS as a marker. PNAS 101, 1453314538.

White, F.M., 1991. Viscous Fluid Flow. McGraw-Hill Book Co., International Edition, $614 \mathrm{p}$.

Willmarth, W.W., Lu, S.S., 1972. Structure of the Reynolds stress near the wall. J. Fluid Mech. 55, 65-92.

Wilson, J.D., Ward, D.P., Thurtell, G.W., Kidd, G.E., 1982. Statistics of atmospheric turbulence within and above a corn canopy. Boundary-Layer Meteorol. 24, 495-519.

Wilson, J.D., 2000. Trajectory models for heavy particles in atmospheric turbulence: comparison with observations. J. Appl. Meteorol. 30, 1894-1912.

Wolfenbarger, L.L., Phifer, P.R., 2000. The ecological risks and benefits of genetically engineered plants. Science 290, 20882093.

Yang, T.S., Shy, S.S., 2005. Two-way interaction between solid particles and homogeneous air turbulence: particle settling rate and turbulence modification measurements. J. Fluid Mech. 526, 171-216. 
Zhu, W., van Hout, R., Luznik, L., Kang, H.S., Katz, J., Meneveau, C., 2006. A comparison of PIV measurements of canopy turbulence performed in the field and in a wind tunnel model. Exp. Fluids 41, 309-318.

Zhu, W., van Hout, R., Katz, J., 2007a. PIV measurements in the atmospheric boundary layer within and above a mature corn canopy. Part II. Quadrant-Hole analysis. J. Atmos. Sci. 64, 2825-2838 doi:10.1175/JAS3990.1.

Zhu, W., van Hout, R., Katz, J., 2007b. On the flow structure and turbulence during sweep and ejection events in a windtunnel model canopy. Boundary-Layer Meteorol. 127, 205-233. 